Open Access

\title{
Dopamine agonist inhibits vascular endothelial growth factor protein production and secretion in granulosa cells
}

Hortensia Ferrero ${ }^{1,2^{*}}$, Carmen M. García-Pascual ${ }^{1,2}$, Nuria Pellicer' ${ }^{1}$, Carlos Simón ${ }^{1,2}$, Antonio Pellicer ${ }^{1,3}$ and Raúl Gómez²

\begin{abstract}
Background: Dopamine receptor 2 agonists (D2-ags) inhibit vascular endothelial growth factor (VEGF) secretion in luteinized granulosa cells (LGCs) both in vitro and in vivo. However, the mechanism of D2 regulation of the VEGF/ VEGF Receptor 2 (VEGFR-2) pathway remains to be elucidated. We sought to determine the effects of D2 signaling on VEGF transcription and translation in LGCs, with the expectation of identifying potential D2-ag-based therapies for ovarian hyperstimulation syndrome (OHSS).

Findings: LGCs from egg donors were cultured with chorionic gonadotropin ( $h C G$ ) in the presence of Actinomycin-D (ActD) or Brefeldin-A (BFA) to evaluate the effects of a D2-ag, cabergoline (Cb2), on VEGF secretion. The contribution of the conventional $G_{i} / G_{0}, G_{z}$ and $A K T / \beta$-Arrestin pathways in the VEGF regulation was assessed by adding pertussis toxin (PTX), phorbol 12-myristate 13-acetate (PMA), or wortmannin (WT). While Cb2 inhibited VEGF secretion by interfering with VEGF peptide translation and secretion, inhibition of conventional D2 transduction pathways did not reverse Cb2mediated inhibition of VEGF secretion.

Conclusions: The effects of D2-ag on VEGF translation and secretion are mediated by D2 signaling pathways that have yet to be described. We found that D2-ag inhibits VEGF secretion at the post-transcriptional level, suggesting that D2-ag treatment should be combined with therapies that inhibit VEGF transcription, such as the employment of LH or GnRH for triggering ovulation, to improve the efficacy of OHSS prevention.
\end{abstract}

Keywords: OHSS, VEGF, Granulosa cells, Dopamine receptor 2, Dopamine receptor-2 agonist

\section{Findings}

Ovarian hyperstimulation syndrome (OHSS) is an iatrogenic complication of ovarian stimulation associated with the use of human chorionic gonadotropin (hCG), is characterized by an increase in vascular permeability (VP) [1]. Vascular endothelial growth factor (VEGF) is an important component in the development of OHSS [2, 3]. Besides, it has been demonstrated that hCG administration increases VEGF mRNA expression in luteinized granulosa cells (LCGs) [4, 5]. Several studies have attempted to avoid an increase in VEGF while employing GnRH agonists to induce ovulation [6,7]; however, this strategy does not

\footnotetext{
* Correspondence: hortensia.ferrero@ivi.es

${ }^{1}$ Fundación IVI, C/ Catedrático Agustín Escardino, n9, Paterna, Valencia 46980, Spain

${ }^{2}$ Instituto Universitario IVI/ INCLIVA, Valencia 46015, Spain

Full list of author information is available at the end of the article
}

totally avoid OHSS onset [8], leaving a need for treatments that block VEGF/VEGF receptor 2 (VEGFR2) signaling completely.

Several in vivo $[9,10]$ and in vitro studies [11] have suggested a role for dopamine in the regulation of the VEGF/VEGFR2 pathway. Interestingly, high levels of dopamine are present in follicular fluid and human ovarian biopsies [12,13], and dopamine receptors have been found on human granulosa cells (GCs) [14]. Previous studies suggest a role for dopamine receptor agonist (D2-ag) in preventing VP increases $[15,16]$ by inhibiting VEGF secretion $[17,18]$. However, D2-ag has previously been shown to block the onset of early-stage OHSS in $50 \%$ of women at risk for developing the condition, but it was not effective in preventing the late onset form [19]. Understanding the molecular mechanisms involved 
in D2 regulation of VEGF is critical to elucidating the role of D2-ag in OHSS prevention. Therefore, the goal of this study was to determine the molecular mechanism through which D2-ag inhibits VEGF secretion and to establish which D2 signaling pathways described in D2expressing cells (Gi/Go, Gz and AKT/ $\beta$-Arrestin) [20] are involved in the regulation of VEGF secretion.

LGCs were obtained from 24 egg donors [aged 25-30 years, oocytes retrieved $=10-15$, estrogen $\quad(\mathrm{E} 2)<$ $2000 \mathrm{pg} / \mathrm{mL}$, body mass index $(\mathrm{BMI})<30]$. Cells were isolated by filtering [21], then washed and cultured as described below in the different studies. Written informed consent was provided by all participants, and the study protocol was approved by ethics committee of IVI Valencia.

\section{VEGF mRNA is not altered by D2-agonist (Cabergoline)}

Previous studies have suggested that VEGF inhibition by D2-agonist, cabergoline $(\mathrm{Cb} 2)$, is not exerted at the transcriptional level $[14,15]$, so we evaluated whether the half-life of VEGF mRNA remained unaffected by D2-ag administration to LGCs. LGCs $(N=6)$ were pre-incubated with $5 \mu \mathrm{g} / \mathrm{mL}$ Actinomycin-D (ActD) (Sigma-Aldrich, St. Louis, MO) for $2 \mathrm{~h}$ to inhibit de novo transcription. Supernatant was removed and LGCs were incubated in the presence or absence of $\mathrm{Cb} 2(100 \mu \mathrm{M}$; Pharmacia \& Upjohn, North Peapack, NJ, USA) with $5 \mathrm{IU} / \mathrm{mL}$ hCG (Profasi; Serono Laboratories, Madrid, Spain) and $5 \mu \mathrm{g} / \mathrm{mL}$ ActD for 1, 2, or 4 h. VEGF (Hs00900055_m1) and $\beta$-actin (Hs99999903_m1) expression levels were estimated by quantitative QF-RT-PCR using TaqMan ${ }^{\circ}$ Gene Expression Assays (Applied Biosystems, Carlsbad, CA, USA). No significant differences were observed by a Student's $t$-test in VEGF mRNA (data not shown) or in transcript stability in Cb2-treated LGCs compared to Cb2-untreated LGCs (Fig. 1). These results support our previous suspicious about $\mathrm{Cb} 2$ does not affect at transcriptional level.

D2-ag interferes with VEGF protein production and secretion To determine whether $\mathrm{Cb} 2$ has translational or posttranslational effects on VEGF production, LGCs $(N=6)$ were pre-incubated with a protein secretion inhibitor, Brefeldin-A (BFA; $10 \mu \mathrm{g} / \mathrm{mL}$ ) (Sigma-Aldrich, St. Louis, US, A), for $1 \mathrm{~h}$. Subsequently, LGCs were incubated in the presence or absence of $\mathrm{Cb} 2(100 \mu \mathrm{M})$ with $5 \mathrm{IU} / \mathrm{mL}$ hCG with or without $10 \mu \mathrm{g} / \mathrm{mL}$ BFA for $8 \mathrm{~h}$. Extracellular and intracellular VEGF levels were measured using ELISA kits (R\&D Systems, Minneapolis, US). Intracellular VEGF was confirmed by immunofluorescence using anti-VEGF antibody $(10 \mu \mathrm{g} / \mathrm{mL}$; R\&D Systems Minneapolis, MN) and AlexaFluor594 antibody (1:500; R\&D Systems Minneapolis, US). A fluorescence microscope was used to observe fluorescence (Nikon Eclipse E400, Japan), and images were acquired with a digital camera (Olympus, Tokyo,

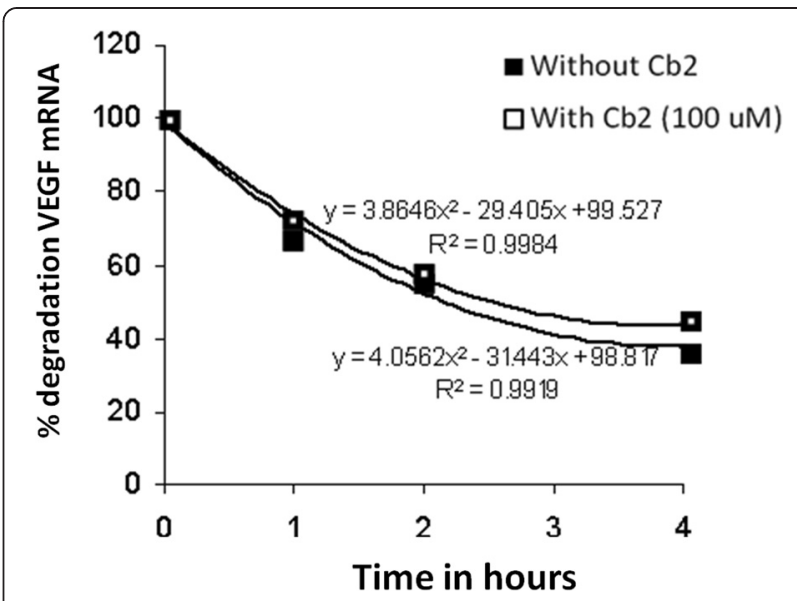

Fig. 1 VEGF $m R$ RA is not altered by the dopamine receptor 2 agonist Cabergoline. Time-course experiments designed to study the effects of the dopamine receptor 2 agonist (D2-ag) Cabergoline (Cb2) on VEGF mRNA stability (expressed as the percentage of VEGF mRNA degradation) in LGCs. LGCs $(n=6)$ were pre-incubated with actinomycin D (ActD), then treated with $\mathrm{Cb} 2$, hCG, and ActD for 1, 2, or $4 \mathrm{~h}$ or untreated. The amount of VEGF CDNA at time point 0 was assigned a value of 100 and the percentage of degraded mRNA was estimated according to variations in the Ct determined by QF-RT-PCR. No significant differences in VEGF mRNA stability were observed in LGCs treated with Cb2 compared to untreated LGCS

Japan). Signal intensity was assessed by Matlab (Worcester, MA), as previously described [22]. The Student's $t$-test was used for statistical analysis and a $p$-value less than 0.05 was considered statistically significant.

In the absence of BFA, extracellular VEGF levels in LGCs not treated with $\mathrm{Cb} 2$ were higher than intracellular VEGF levels, suggesting that most of the VEGF produced by LGCs were secreted (Fig. 2a, c). However, in Cb2-treated LGCs, extracellular and intracellular VEGF levels were similar. Intracellular VEGF levels in these cells were higher than in Cb2-untreated cells (Figs. 2a, c and $3 a, b)$, suggesting that $\mathrm{Cb} 2$ interferes with the secretion of VEGF in LGCs and most of the VEGF produced is not secreted.

When protein secretion was inhibited by BFA, intracellular VEGF levels were lower in $\mathrm{Cb} 2$-treated than in untreated LGCs (Figs. 2b, c and 3a, b), suggesting that D2-ag also acts by inhibiting VEGF peptide production. Although there are studies suggesting that VEGF secretion can be regulated by the dopaminergic system $[9,10]$, none describe the mechanism how D2-agonists inhibit VEGF. In this regard, this is the first study showing that VEGF inhibition by D2-ag is specifically exerted at the posttranscriptional level with effect in of both peptide translation and subsequent releases once it has been produced, suggesting that D2-ag treatment should be combined with therapies to inhibit VEGF transcription, such as LH or $\mathrm{GnRH}$ agonists treatment for triggering ovulation, to improve the efficacy of OHSS prevention [6, 7]. 


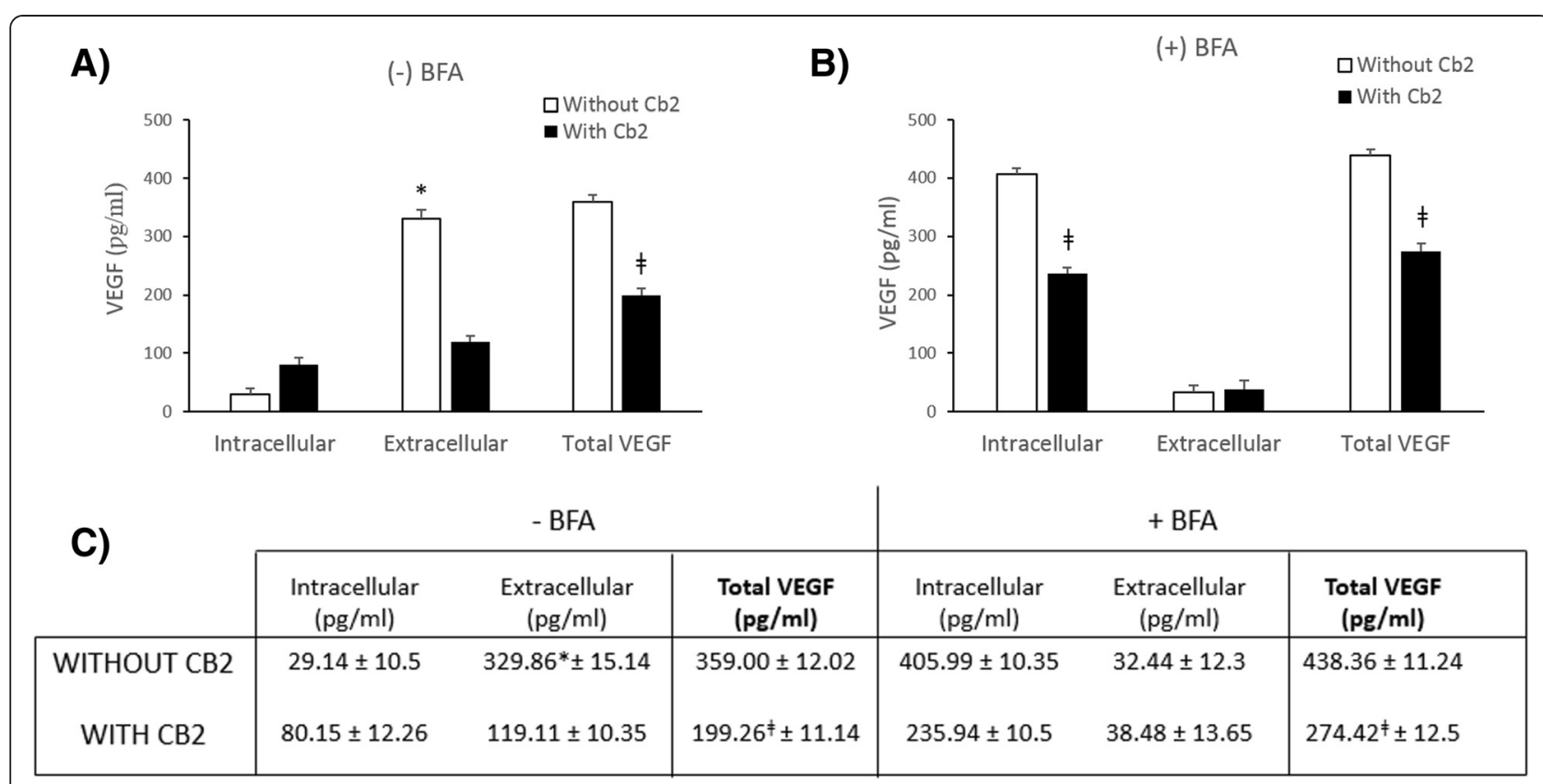

Fig. 2 Post-transcriptional regulation of VEGF by the dopamine receptor 2 agonist, Cabergoline. Intracellular and extracellular quantification of VEGF by ELISA in LGCs $(n=6)$ cultured for $8 \mathrm{~h}$ in hCG with or without Cb2 in the (a) absence or (b) presence of BFA. c Intracellular, extracellular, and total VEGF levels expressed as pg/mL (mean $\pm S D$ ). In the absence of BFA (-) extracellular VEGF in Cb2-untreated LGCs were higher than intracellular VEGF levels. However, in the presence of BFA (+) the intracellular VEGF in Cb2-treated LGCs is lower than in Cb2-untreated cells. ${ }^{\ddagger} p<0.05$ compared to VEGF levels in Cb2-treated LGCs vs Cb2-untreated LGCs; ${ }^{*} p<0.05$ compared to intracellular vs extracellular VEGF levels in absence of BFA

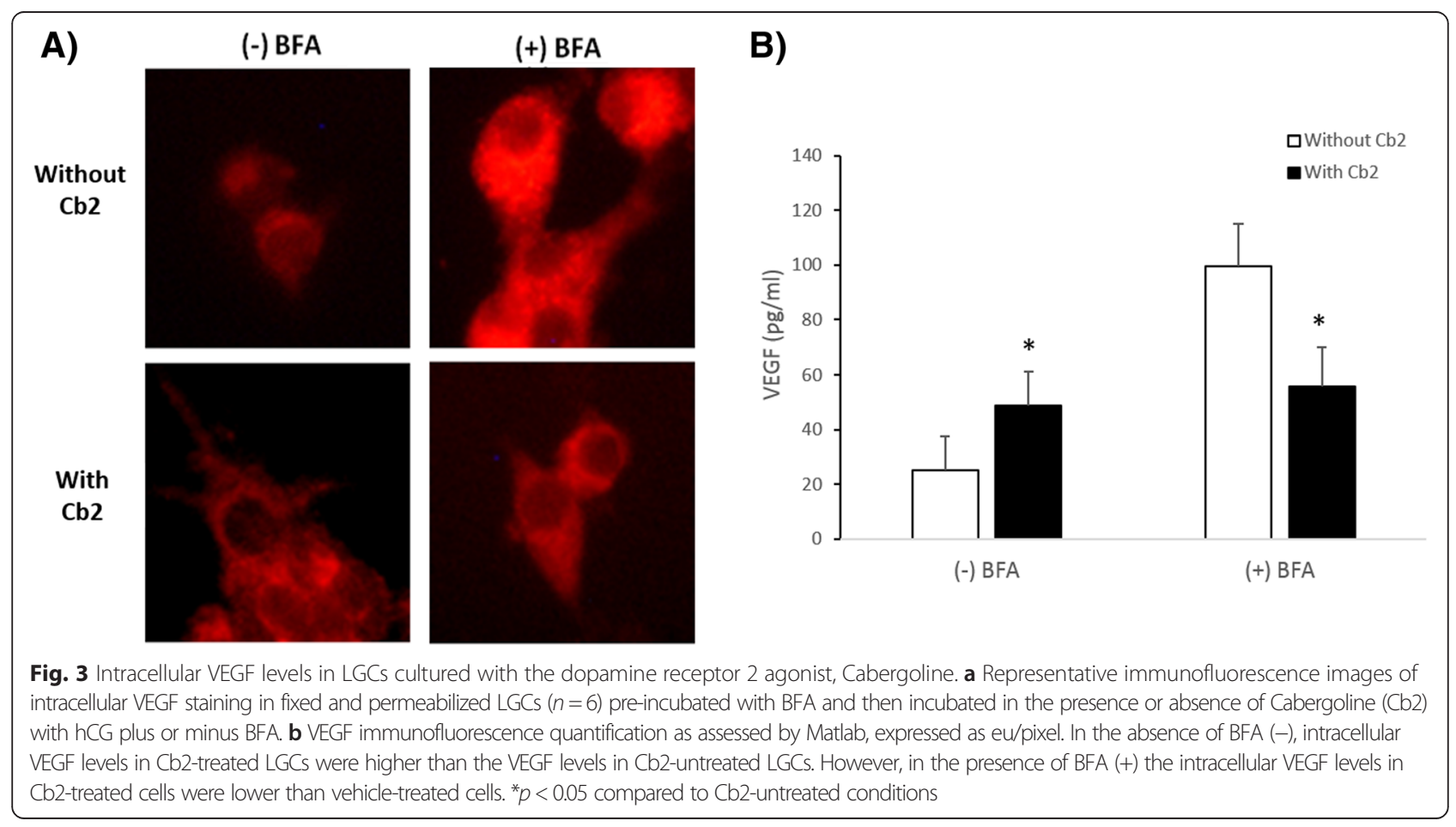


The role of the conventional D2 transduction pathways in the modulation of VEGF secretion mediated by D2-ag

To determine whether the conventional D2 transduction pathways (Fig. 4a) described in D2 expressing cells [16] are involved in D2-mediated post-transcriptional VEGF regulation, LGCs $(N=6)$ were incubated with $5 \mathrm{IU} / \mathrm{mL}$ hCG in the presence or absence of Cb2 $(100 \mu \mathrm{M})$ with or without $200 \mathrm{ng} / \mathrm{mL}$ pertussis toxin (PTX; a $G_{i / o}$ pathway inhibitor), $100 \mathrm{ng} / \mathrm{mL}$ phorbol 12-myristate 13-acetate (PMA; $G_{z}$ pathway inhibitor) or $10 \mu \mathrm{M}$ wortmannin (WT; a AKT/ $\beta$-arrestin complex inhibitor) (Sigma-Aldrich, St. Louis, MO, USA) for $48 \mathrm{~h}$. ELISA kit was used to quantify protein production and secretion and a Student's $t$-test was used to determine statistical significance. Inhibition of these three different pathways failed to counteract the effects of $\mathrm{Cb} 2$ on the ability of LGCs to secrete VEGF (Fig. 4b).

Based on our previous findings [17] it is unlikely that the D2 receptor is not involved in the process. Since the Gi/o, $\mathrm{Gz}$, and $\mathrm{AKT} / \beta$-arrestin signaling pathways are common intermediaries, it is possible that its inhibition might also be acting on pathways other than those transduced by D2, which might be involved in the VEGF regulation in LGCs. Therefore, it could explain why was not observe a counteracting increase in VEGF in response to treatment with PTX, PMA, or WT. The VEGF inhibition observed may be a result of D2-agonist-mediated transduction pathways that have yet to be described or alternative mechanisms that could be acting in well-known VEGF signaling pathways, such as FAK and MAPK pathways [23], PCL/PKC/Sp1 and adenylate cyclase/PKA/CREB pathways [24], or PI3k/AKT pathway [25]. We are unaware whether VEGF regulation by D2-ag is a universal mechanism of angiogenesis control in many types of cells and conditions. If so, our findings, even if non-conclusive, could be useful at least to identify possible candidates involved in the process.

D2-agonists have also been considered for the treatment of tumorigenic conditions, such as ovarian cancer [26], in which the deregulation of the VEGF/VEGFR-2 pathways plays a major role. In this regard, investigation

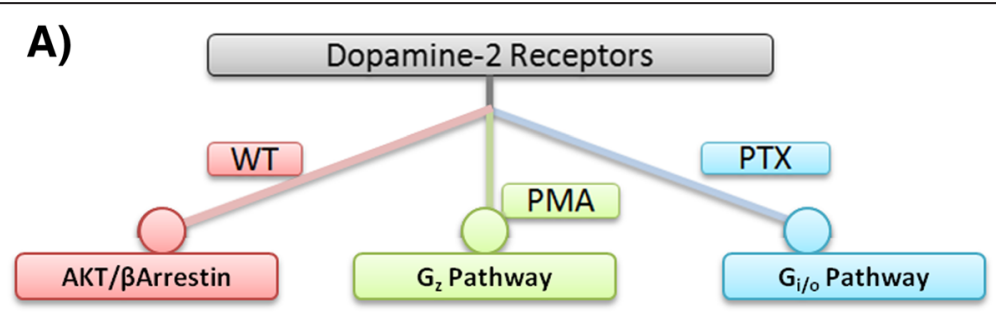

\section{B)}

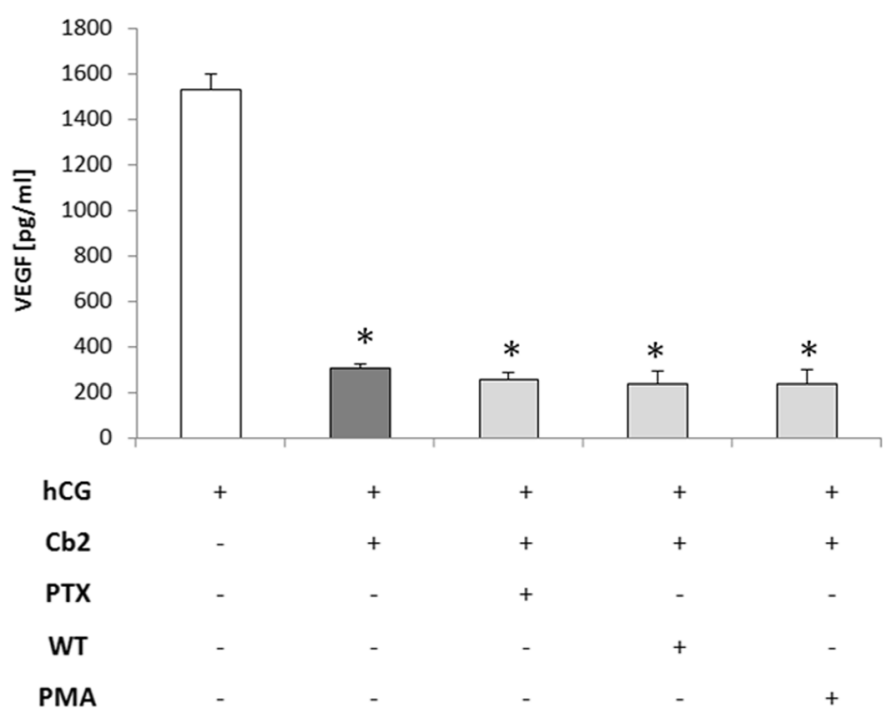

Fig. 4 D2-downstream pathway inhibitors do not affect LGC VEGF secretion in vitro. a Conventional pathways through which D2 signals are transduced and the inhibitors commonly used to block them; PTX = pertussis toxin, WT = wortmannin, and PMA = phorbol 12-myristate 13-acetate (circles indicate inhibitory actions). Each of these compounds inhibits one of the D2-downstream pathways. b VEGF secretion levels measured by ELISA (expressed as picograms per milliliter) from LGCs $(n=6)$ cultured with hCG in the presence or absence of Cabergoline (Cb2) and PTX, WT, or PMA. Inhibitors of D2-downstream pathways did not reverse the effect of D2-ag on VEGF secretion. ${ }^{*} p<0.01$, compared to the (control) D2-ag treated (blank bar) group 
of the mechanism by which VEGF secretion is regulated by the dopaminergic system is needed to provide a basis for more specific therapies to treat diseases related to VEGF-mediated vascular angiogenesis, including OHSS.

Based on our findings, D2-ag in conjunction with clinical strategies aimed at reducing VEGF mRNA levels may provide a more powerful inhibitory effect on VEGF and improve efforts to prevent OHSS.

\section{Competing interests}

The authors declare that they have no competing interests.

\section{Authors' contributions}

HF was involved in the study design, acquisition of data, analysis and interpretation of data, and paper drafting. CMG-P and NP were involved in acquisition data and analysis. CS contributed to data interpretation. AP and RG devised and supervised the study and contributed to the interpretation of the data. All authors read and approved the final manuscript.

\section{Acknowledgements}

We thank Monterde Mercedes from Hospital La Fe for her assistance in the statistical analysis. We also give special thanks to all the medical and technical staff at the IVI clinic for their assistance in obtaining follicular fluid samples. This work was supported by the Spanish Ministry of Economy and Competitiveness through the Miguel Servet Program [CP13/00077]; Carlos III Institute of Health grant [PI14/00547] awarded to R.G. and Spanish National and Valencian State Governments through SAF2008-03546 and Prometeo (20100613) grants awarded to A.P.

\section{Author details}

${ }^{1}$ Fundación IVI, C/ Catedrático Agustín Escardino, n9, Paterna, Valencia 46980, Spain. ${ }^{2}$ Instituto Universitario IVI/ INCLIVA, Valencia 46015, Spain. ${ }^{3}$ Hospital Universitario i Politécnico La Fe, Valencia 46026, Spain.

Received: 24 July 2015 Accepted: 3 September 2015 Published online: 17 September 2015

\section{References}

1. Kaiser UB. The pathogenesis of the ovarian hyperstimulation syndrome. N Engl J Med. 2003;349:729-32

2. Bates DO, Curry FE. Vascular endothelial growth factor increases hydraulic conductivity of isolated perfused microvessels. Am J Physiol. 1996;271:H2520-8.

3. Ferrara N, Henzel WJ. Pituitary follicular cells secrete a novel heparin-binding growth factor specific for vascular endothelial cells. Biochem Biophys Res Commun. 1989;161:851-8.

4. Neulen J, Yan Z, Raczek S, Weindel K, Keck C, Weich HA, et al. Human chorionic gonadotropin-dependent expression of vascular endothelial growth factor/ vascular permeability factor in human granulosa cells: importance in ovarian hyperstimulation syndrome. J Clin Endocrinol Metab. 1995:80:1967-71.

5. Wang TH, Horng SG, Chang CL, Wu HM, Tsai YJ, Wang HS, et al. Human chorionic gonadotropin-induced ovarian hyperstimulation syndrome is associated with up regulation of vascular endothelial growth factor. J Clin Endocrinol Metab. 2002:87:3300-8.

6. Haas J, Ophir L, Barzilay E, Yerushalmi GM, Yung Y, Kedem A, et al. GnRH agonist vs. hCG for triggering of ovulation differential effects on gene expression in human granulosa cells. PLoS One. 2014;9, e90359.

7. Kitajima Y, Endo T, Manase K, Nishikawa A, Shibuya M, Kudo R. Gonadotropinreleasing hormone agonist administration reduced vascular endothelial growth factor (VEGF), VEGF receptors, and vascular permeability of the ovaries of hyperstimulated rats. Fertil Steril. 2004:81 Suppl 1:842-9.

8. Youssef MA, Van der Veen F, Al-Inany HG, Mochtar MH, Griesinger G, Nagi Mohesen $\mathrm{M}$, et al. Gonadotropin-releasing hormone agonist versus HCG for oocyte triggering in antagonist-assisted reproductive technology. Cochrane Database Syst Rev. 2014;10, CD008046.

9. Basu S, Nagy JA, Pal S, Vasile E, Eckelhoefer IA, Bliss Vs et al. The neurotransmitter dopamine inhibits angiogenesis induced by vascular permeability factor/vascular endothelial growth factor. Nat Med. 2001;7:569-74.
10. Cristina C, Díaz-Torga G, Baldi A, Góngora A, Rubinstein M, Low MJ, et al. Increased pituitary vascular endothelial growth factor-a in dopaminergic D2 receptor knockout female mice. Endocrinology. 2005;146:2952-62.

11. Sinha S, Vohra PK, Bhattacharya R, Dutta S, Sinha S, Mukhopadhyay D. Dopamine regulates phosphorylation of VEGF receptor 2 by engaging Src-homology-2-domain-containing protein tyrosine phosphatase 2. J Cell Sci. 2009;122:3385-92.

12. Bodis J, Bognar Z, Hartmann G, Torok A, Csaba IF. Measurement of noradrenaline, dopamine and serotonin contents in follicular fluid of human graafian follicles after superovulation treatment. Gynecol Obstet Invest. 1992;33:165-7.

13. Lara HE, Porcile A, Espinoza J, Romero C, Luza SM, Fuhrer J, et al. Release of norepinephrine from human ovary: coupling to steroidogenic response. Endocrine. 2001;15:187-92.

14. Rey-Ares V, Lazarov N, Berg D, Berg U, Kunz L, Mayerhofer A. Dopamine receptor repertoire of human granulosa cells. Reprod Biol Endocrinol. 2007:5:40.

15. Gómez R, Gonzalez-Izquierdo M, Zimmermann RC, Novella-Maestre E, Alonso-Muriel I, Sanchez-Criado J, et al. Low dose dopamine agonist administration blocks VEGF mediated vascular permeability without altering VEGFR-2 dependent luteal angiogenesis in a rat ovarian hyperstimulation model. Endocrinology. 2006;147:5400-11.

16. Álvarez C, Martí-Bonmatí L, Novella-Maestre E, Sanz R, Gómez R, Fernández-Sánchez $M$, et al. Dopamine agonist cabergoline reduces hemoconcentration and ascites in hyperstimulated women undergoing assisted reproduction. J Clin Endocrinol Metab. 2007;92:2931-7.

17. Ferrero H, García-Pascual CM, Gómez R, Delgado-Rosas F, Cauli O, Simón C, et al. Dopamine receptor 2 activation inhibits ovarían vascular endothelial growth factor secretion in vitro: implications for treatment of ovarían hyperstimulation syndrome with dopamine receptor 2 agonists. Fertil Steril. 2014;101:1411-8.

18. Ferrero H, García-Pascual CM, Gaytán M, Morales C, Simón C, Gaytán F, et al. Dopamine receptor 2 activation inhibits ovarian vascular endothelial growth factor secretion in an ovarian hyperstimulation sysndrome (OHSS) animal model: implications for treatment of OHSS with dopamine receptor 2 agonists. Fertil Steril. 2014;102:1468-76.

19. Youssef MA, Van Wely M, Hassan MA, Al-Inany HG, Mochtar M, Khattab S, et al. Can dopamine agonists reduce the incidence and severity of OHSS in IVF/ICSI treatment cycles? A systematic review and meta-analysis. Hum Reprod Update. 2010;16:459-66.

20. Gonzales-Iglesias AE, Murano T, Li S, Tomic M, Stojilkowic SS. Dopamine inhibits basal prolactin release in pituitary lactotrophs through pertussis toxin-sensitive and insensitive signaling pathways. Endocrinology. 2008;149:1470-9.

21. Ferrero H, Delgado-Rosas F, Garcia-Pascual CM, Monterde M, Zimmermann RC, Simón C, et al. Efficiency and purity provided by the existing methods for the isolation of luteinized granulose cells: a comparative study. Hum Reprod. 2012;27:1781-9.

22. Matkowskyj KA, Schonfeld D, Benya RV. Quantitative immunohistochemistry by measuring cumulative signal strength using commercially available software photoshop and matlab. J Histochem Cytochem. 2000;48:303-12.

23. Sarkar C, Chakroborty D, Basu Mitra R, Banerjee S, Dasgupta PS, Basu S. Dopamine in vivo inhibits VEGF-induced phosphorylation of VEGFR-2, MAPK, and focal adhesion kinase in endothelial cells. Am J Physiol Heart Circ Physiol. 2004;287:H1554-60

24. Chen SU, Chou CH, Lin CW, Lee H, Wu JC, Lu HF, et al. Signal mechanisms of vascular endothelial growth factor and interleukin-8 in ovarian hyperstimulation syndrome: dopamine targets their common pathways. Hum Reprod. 2010;25:757-67.

25. Stocco C, Telleria C, Gibori G. The molecular control of corpus luteum formation, function, and regression. Endocr Rev. 2007;28:117-49.

26. Moreno-Smith M, Lee SJ, Lu C, Nagaraja AS, He G, Rupaimoole R, et al. Biologic effects of dopamine on tumor vasculature in ovarian carcinoma. Neoplasia. 2013;15:502-10. 